\title{
Key Roles and Process to Foster Successful Firm - University Collaborations: The CEMEX Case
}

\author{
Myrna Flores $^{1}$, Daniel Guevara ${ }^{2}$, and Martin Herrera ${ }^{1}$ \\ ${ }^{1}$ CEMEX Research Group AG, Switzerland \\ ${ }^{2}$ KM-IC Research \\ myrflores@hotmail.com, despejelg@gmail.com, \\ martinadolfo.salado@cemex.com
}

\begin{abstract}
In 2007 the Processes and IT area in CEMEX launched an Open Innovation Strategy to collaborate with external experts such as universities, consultants and associations at a global level in key strategic topics. As a result, a portfolio of more than 50 collaborative research projects has been launched in particular with different academic organizations mainly in Europe and Mexico. Different lessons learned have been obtained, but one of the most relevant ones, has been the acknowledgement of different ways to manage collaborative research projects according to the business opportunities and the need to identify a process and roles to enable successful collaborations. Such collaborative spaces enable the sharing and co-creation of knowledge and the emergence of knowledge markets where intellectual capital is co-developed. This paper proposes a process to enable firms collaborate with Universities to deploy an open innovation model and the actors enabling it.
\end{abstract}

Keywords: Firm - University Collaboration, Open Innovation, Knowledge Markets, Knowledge Seeker, Broker, IP Entrepreneur.

\section{Introduction}

Growing global competition requires companies to be more competitive, improving their productive and business processes to operate in a leaner way. Enterprises are constantly under pressure not only to offer high quality products with competitive prices, but also to be constantly innovative offering new products and services to the international and borderless markets.

Research and Development to achieve innovations is a very costly, risky and lengthy process. As a consequence, it is difficult and challenging for companies to innovate in short periods of time in an ever increasing global market where customers' needs change quickly and the products' life cycles get shorter (Flores M. 2006a, Flores M. 2006d).

In this context, Henry Chesbrough from the University in Berkley defined the traditional innovation process as a Closed Innovation Model. The reason is that all innovation activities are located inside the company from the ideas creation, development process, sales and marketing. In this case, companies think that they are 
the best on their field; they have enough knowledge and resources inside their firm boundaries to develop such new solutions. Although this innovation model has been followed by many companies he argues that it cannot satisfy the fast changing demands of global customers in a changing society. As a result, Henry Chesbrough (2003) proposed a new concept which we coined the Open Innovation model as the use of purposive inflows and outflows of knowledge to accelerate internal innovation, and expand the markets for external use of innovation.

Universities play a critical role as a source of fundamental knowledge, therefore should contribute in the formation of new collaborative environments increasing the innovation capabilities and continuous improvement. Universities can in fact be considered as a focal element for the development and dissemination of new knowledge and technologies for the design, development and commercialization of new products and processes (Flores, 2006b, Flores, 2006c).

Several highly innovative companies, such as Nokia, IBM, Intel, General Electric, among many others, have developed open innovation strategies to launch joint initiatives with Universities to catalyze their innovation process. As a result, CEMEX Processes \& IT has launched more than 50 collaborative projects since 2004 with different Universities, Consultants and Associations in the Americas and Europe. Additionally, the role of Business Process Research and Networking Sr. Consultant was integrated in the Processes \& IT team to coordinate the open innovation efforts.

One of the lessons learned of these latter collaborations is the definition of a clear process for CEMEX in which projects' outputs can be translated into valuable intangible assets which match the following criteria:

- It Must Add Value: it does not need to be new but it must at least represent an enhancement developed by CEMEX over an existing tool or process.

- It Must Be Useful: Intangible Assets are not measured by their cost but by their usefulness; usefulness means that it must enhance CEMEX operations, like increase efficiency, lower costs, etc.

- It Must Be Shareable: it should be helpful for at least two CEMEX Business Units

Furthermore, and part of the collaborative context, there are two additional concepts that are relevant while co-developing new intangibles; these latter are known as the Knowledge Market and the Intellectual Capital. A Knowledge Market fosters to create the knowledge required to innovate and therefore create more value. It is characterized by informal or formal relationships between independent partners, interested to collaborate in a win-win way.

In such a collaborative space different actors are required, which in most cases are: Knowledge Owner, Seeker, and Broker. Within the context of the CEMEX Research and Networking model, in the next section different roles have been identified to enable successful collaborations.

One outcome of the Industry-University collaboration is related to intangibles creation. A way to identify those intangibles created and also to measure their value contribution is through the Intellectual Capital. This approach groups all the intangibles in three, as follows (Guevara, 2011):

- Human Capital: This group includes the different assets of the person, such as knowledge backlog coming from training, skills, innovation competency, among 
others. Also, this group is part of the core competence underpinnings of the organization and it is rented to the business. In other words, the human capital includes those assets that return home after the business day is closed.

- Structural Capital: This group includes all of those assets that remain at the organization, as some could say that reside inside the walls right after persons go home. Here are included all processes, methods, systems and also intellectual property such as patents and trademarks.

- Relational Capital: Among the human and structural capital, there is another group of intangibles that has a direct relation to the activities employees perform outside the organization that involves external entities such as customers, government authorities, communities, etc.

This grouping method is considered to identify the value contribution of intangible assets in the organization.

\section{Inputs, Outputs and Key Roles to Enable an Open Innovation Model}

As a result of the lessons learned of approximately 50 different collaborative research projects carried out with several Universities since 2007 and based on a detailed literature review analysis, the following are proposed as key elements and actors to enable successful and sustainable open innovation projects in which both tacit and explicit knowledge is exchanged among them to obtain the expected results.

1. Input: a technical or business problem to be solved and the knowledge required to solve it

2. Knowledge Seeker: Entity or person with the need to resolve a technical or business problem using external resources applying the Open Innovation model. This actor belongs normally to the Firm and will become part of its R\&D projects.

3. Knowledge Owner: Entity or person with the technical or business knowledge needed to resolve the Seeker's problems while using public or private funds to perform the required research. This actor in many cases is a researcher from a University, and could also be a consultant or an expert working in an Association or any other organization.

4. Knowledge Broker: Entity or person that bridges and manages the collaboration between the Owners and the Seekers. Also and before the collaboration between the Firm and the University starts, it is its responsibility to establish and agreement between the Firm and the University around the final intangibles expected due to the collaboration, as well as the commercial strategy of the new Intellectual Property (IP) created, whereas the IP is the formal documentation for the intangibles co-created or enhanced. However and depending on their functions and responsibilities, this role could be divided in two: one for the Firm and the second for the University side.

a) Firm Broker: The broker at the firm will facilitate the right understanding of the problem to clarify the project objectives and scope to look for an external partner. This latter will make sure that the knowledge owner has the right competencies and expertise to start a collaboration with the Seeker. In such context, the broker should focus so that that the Seeker and Owner collaborate to solve the problem. For that 
purpose a collaborative plan with key milestones will be defined in which both sides commit to deliver the outcomes.

b) University Broker: As in the case of the Firm, it has been observed that some Universities count with specialized brokers that look forward to match the knowledge developed in the University to sell it externally and develop a knowledge market in the form of IP, Licenses, basic or consulting projects to solve problems in the Industry,

5. Intellectual Property Entrepreneur: Entity or person in charge of selling/buying the IP generated during or after collaboration, as agreed by the Brokers and must be settled before the collaboration starts. It is responsible of royalties' agreements and contractual terms and conditions for licensing IP. This actor is found in some firms, for example this is an important role within CEMEX Research Group organization.

6. Output (Intangible Assets): The main deliverable of the collaboration turned as intellectual property (IP) that fulfills the requirements to be commercialized.
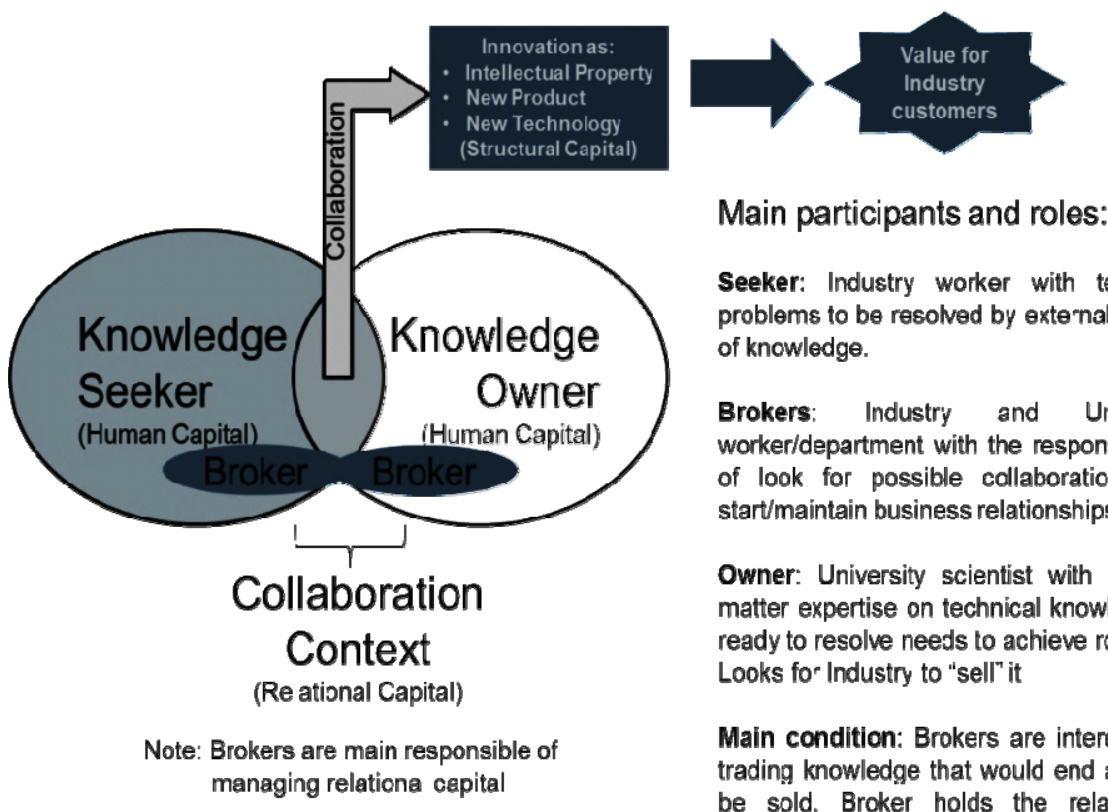

Seeker: Industry worker with technical problems to be resolved by extenal source of knowledge.

Brokers: Industry and University worker/department with the responsibilities of look for possible collaborations and start/maintain business relationships

Owner: University scientist with subjectmatter expertise on technical knowledge is ready to resolve needs to achieve royalties. Looks for Industry to "sell" it

Main condition: Brokers are interested in trading knowledge that would end as IP to be sold. Broker holds the relationship before, during and after the collaboration

Fig. 1. Key Roles to enable an Open Innovation Model for the Firm - University

Figure 1 depicts how the actors interact under a co-development environment to create a knowledge market. In here are identified the three types of the Intellectual Capital that are developed during the knowledge exchanges among the different actors. For example, as soon as the project is kicked off, the Human Capital intangibles are "adjusted" or enhanced at the Seeker and Owner roles; this is due to the fact that their interactions would transfer and enrich the knowledge, experience and others that are hold by the actors. 
Similar to the enhancements of the intangibles belonging to the Human Capital, there are other intangible improvements on the Intellectual Capital. Continuing with figure 1, there are shown some relevant outcomes of the collaboration and they are related to the intangibles of the Structural Capital group. For this type are considered new patents, products, or technology that creates more value for the Firm. Moreover, the Relational Capital intangibles are enhanced as well. The improvements are more related to the relationships of the actors, and also to external entities such as new customer relationship. Regardless of the group of intangibles, it is important to highlight that the intangibles enhanced or created after and during the collaboration have a direct and high impact on the business value creation.

\section{A Ten Step Generic Process to Co-create Intangible Assets}

The different actors in the collaborative open innovation context interact among them in order to create value for both organizations. However, the interactions should be organized in a structured way to increase the expected successful outcome, which is to solve a problem and develop intangible assets that could be further replicated in a company or third parties.

In this section a ten step generic process is proposed by the authors for an effective collaboration (Edmondson et al, 2012; Fisher and Atkinson-Grosjean, 2002; Perkmann et al, 2011; Pertuzé, 2005).

Step 1 Identify the Need for Collaboration: In this step one of the actors, such as the Seeker, Owner or Broker identifies a technical or business knowledge gap. Within the firm, the knowledge seeker is motivated to search for external collaboration to develop a solution taking advantage of knowledge or expertise created previously by the owner.

Step 2 Request to Solve the Problem with External Knowledge: This step requires a formalization and clear definition of the problem or need to be solved during the collaborative project with the usage of external knowledge. The project objective, scope and key deliverables are defined. Also, at this point the need is translated in an ad-hoc and common "language" that could be understood between the Seeker and the Owner. In CEMEX, to facilitate the problem definition, the firm broker provides standard templates that have been designed to support the knowledge seeker define the problem in a simple way.

Step 3 Identify and Select Knowledge Owners: Once the problem is clarified between the Seeker and the Firm Broker, the next step is to identify the Owner who counts with the most advanced experience to solve the problem. In many cases knowledge owners are recognized by their high quality of publications either in journals, books or conference presentations. In CEMEX, the Broker is responsible of this activity.

Step 4 Bridge Seeker and Owner: In this step the connections between the Seeker and the Owner are built and formalized. Person-to-person interactions emerge; for example, the Seeker would be a Firm employee, and for the Owner would be the subject-matter expert or scientist in the University. In this step the working plan, 
deliverables, culture matching and intellectual property strategy are formalized and documented in detail. The interactions management and collaboration working plan and deliverables would be performed and monitored preferably by the Broker. Also and as part of the Broker functions, at this step all necessary agreements are established for the collaboration and they must be related to the final intangibles expected as co-created or enhanced due to the collaboration; also here is agreed the Intellectual Property (IP) strategy and partition of possible royalties if commercialized. It is important to remark that the owner of the IP must be CEMEX.

Step 5 Collaborate to Co-create Intangible Assets: The Seeker and Owner start collaborating accordingly to the plan and deliverables as intangible assets should be co-developed on time. During this step it is relevant to monitor the trustiness between Seeker and Owner, the interactions accordingly to the working plan, and it is also very important to verify the high quality of the knowledge transferred; all these activities are performed by the Broker. Additionally, is important to mention that in CEMEX the LEAD (Learn, Energize, Apply and Diffuse) project management methodology (Flores 2009) has been developed and implemented to facilitate seekers and owners to collaborate with a clear deliverables and milestones to be delivered by the CEMEX-University teams.

Step 6 Deliver Knowledge Assets as Intangibles: This is almost the final step of the collaboration. Here arise all the intangibles co-created by the interactions. The new intangibles should be protected according to the firm's IP strategy; or it could be as new knowledge appropriation, implying that Owner knowledge is adequate to technical problem description and uses license from Owner by Seeker.

Step 7 Select Relevant Intangibles: The results of the firm-university collaborative project will be assessed to identify if they can be considered intangibles. Those that are relevant for the Firm should be documented and protected and might be also commercialized depending on the firm's IP strategy.

Step 8 Protect Intellectual Property: After the intangibles resulting from the collaboration have been selected, at this step is implemented an agreed strategy to protect them and sell or license the intellectual property as follows: New process, model, product, brand, among others. However, the IP protection could be such as new process, model or operating system as Trade Secret, product or material as Patent or Trademark, and also software or document as Copyright. It is important to clarify the IP strategy and proportionality before starting the project. At this point, the IP Entrepreneur is involved in the process to let the firm's Broker know about new intangibles protected as IP.

Step 9 Monitor Intangibles Performance: The new knowledge co-created as intangibles should be monitored as intangible assets using an open innovation scorecard classifying them into the three Intellectual Capital groups presented before: Human, Structural or Relational. Also, it is recommended that the Broker monitors the intangibles created and transferred internally and externally to the organization.

Step 10 Commercialize IP Internally and Externally: The firm's IP Entrepreneur identifies potential markets to sell or license the intangibles protected as the result of these collaborations. Also and in some cases, this actor identifies and buys or licensees IP coming from other organizations. 


\section{The CEMEX-University Collaboration Process}

Figure 2 presents a 10 steps process that has been followed in most of the collaborations with Universities in order to perform high impact projects for CEMEX. It is important to mention that there could be four potential scenarios triggering the process: 1) The Seeker at CEMEX looking for solutions for the firm, 2) The Owner (researcher at a University) proposing to implement a novelty in CEMEX, 3) The Brokers proposing to test or investigate about a futuristic trend in CEMEX which has not been yet implemented, 4) Solve a gap identified based on the discovery of external best practices or trends. In the process, the dot-lines from step 7 to step 10 highlight the area where intangibles are selected, protected and commercialized. This is because those steps are related to the intangibles management after the collaboration and also are proposed to gain more value after the commercialization of such intangibles.

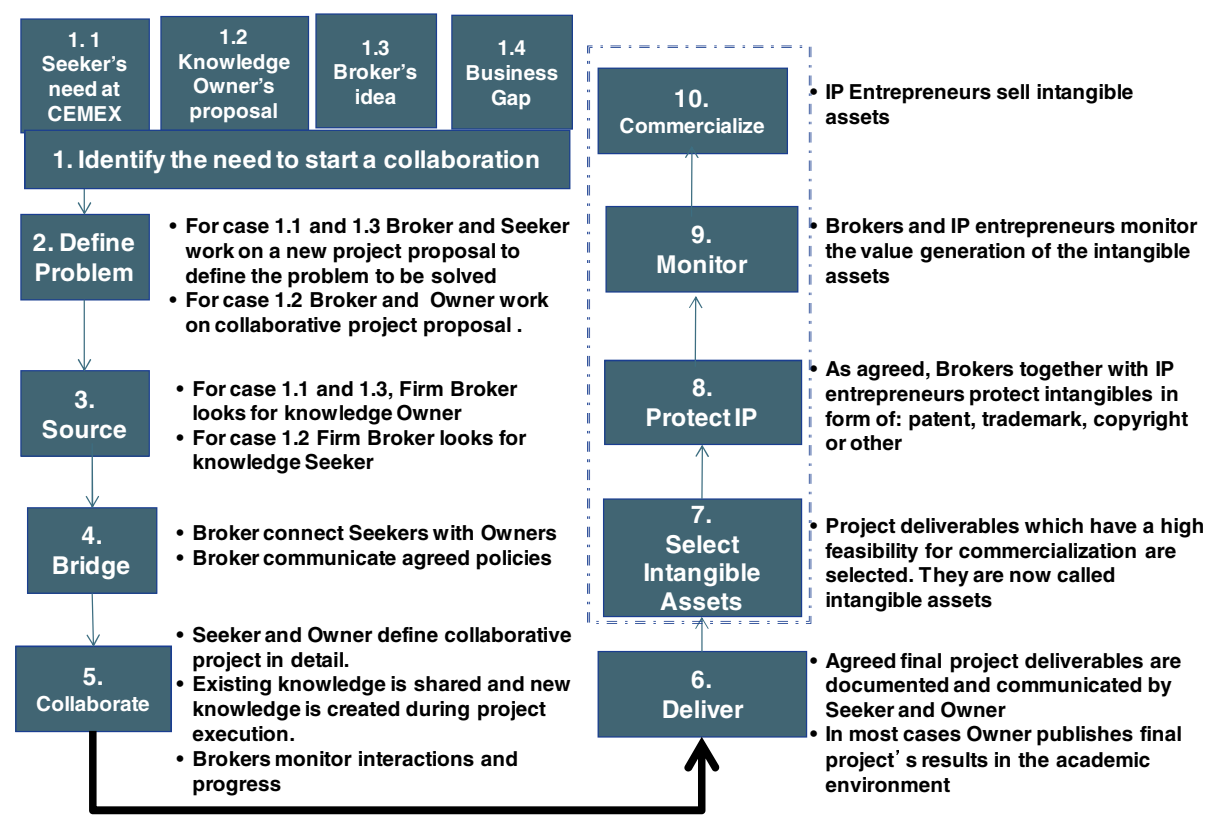

Fig. 2. Proposed Industry University Collaboration process in CEMEX (steps 7 to 10 to be implemented)

\section{Conclusions}

This paper integrates the following three key concepts: Open Innovation, Knowledge Markets and Intellectual Capital as key enablers to co-create intangible assets for CEMEX when collaborating with Universities. It is also highlighted that most innovative firms and Universities require the definition of specific actors such as Knowledge Seekers, Brokers and IP Entrepreneurs. To conclude, a process has been proposed to facilitate firm-university collaboration to co-create intangible assets. 


\section{References}

1. Chesbrough, H.: Open Innovation: The New Imperative for Creating and Profiting from Technology. Harvard Business School Press, Boston (2003)

2. Chesbrough, H.W.: The Era of Open Innovation. Sloan Management Review 44(3), 35-41 (2003)

3. Chesbrough, H.: Open Innovation: How Companies Actually Do It. Harvard Business Review 81(7), 12-14 (2003)

4. Dobbins, M., Robeson, P., Ciliska, D., Hanna, S., Cameron, R., O’Mara, L., DeCorby, K., Mercer, S.: A Description of a Knowledge Broker Role Implemented as part of a Randomized Controlled Trial Evaluating Three Knowledge Translation Strategies. Implementation Science 4, 23 (2009)

5. Edmondson, G., Valigra, L., Kenward, M., Hudson, R.L., Belfield, H.: Making IndustryUniversity Partnerships Works: Lessons from Successful Collaborations. Science Business Innovation Board AISBL (2012)

6. Fisher, D., Atkinson-Grosjean, J.: Brokers on the Boundary: Academy-Industry Liaison in Canadian Universities, vol. 44, pp. 449-467. Kluwer Academic Publisher, Higher Education (2002)

7. Flores, M.: Industry - University Collaboration for Innovation and Regional Development: Evidence From Madras, Monterrey, Milan and Lausanne. Doctoral Thesis Politecnico di Milano (2006a)

8. Flores, M.: Industry - University Collaborative Networks for New Product Development: The Case of IIT Madras, India. Presented at the ICE conference, Milan, June 26-27 (2006b)

9. Flores, M., Cardenas, L.: Industry-University Collaboration in Monterrey, Mexico: Towards an International City of Knowledge. Presented at the Management of Technology (MOT) Conference, Birmingham, UK (September 2006c)

10. Flores, M.: Towards A Taxonomy For Networking Approaches for Innovation. In: Camarinha-Matos, L.M., Afsarmaneshs, H., OIlus, M. (eds.) PROVE 2006. IFIP, vol. 224, pp. 55-66. Springer, Boston (2006)

11. Guevara, D.: Monitoring intellectual capital: a case study of a large company during the recent economic crisis. Doctoral Thesis at Université Paris-Sud XI (2011)

12. Perkmann, M., Neely, A., Walsh, K.: How should Firms Evaluate Success in UniversityIndustry Alliances? A Performance Measurement System. R\&D Management (2011)

13. Pertuzé, J.: Best Practices for Industry-University Research Collaboration. Thesis for Master of Science in Technology at Pontificia Universidad Católica de Chile (2005)

14. Ward, V., House, A., Hamer, S.: Knowledge Brokering: Exploring the Process of Transferring Knowledge into Action. BMC Health Services Research 9, 12 (2009) 